\title{
Medical Emergencies in Dental Practice - A Nepalese study
}

\author{
Dr Sandhya Joshi,' Dr Sudeep Acharya \\ Lecturer, ${ }^{2}$ Associate Professor, Dept. of Oral \& Maxillofacial Surgery, KIST Medical College,
}

Lalitpur, Nepal

Correspondence: Dr Sandhya Joshi; Email: sandhyajo@gmail.com

\section{ABSTRACT}

Introduction: Medical emergencies can occur in dental practice anytime. Changing demographics in the population and increased life expectancy have resulted in more people having medical conditions which predispose to a medical emergency.

Objective: To find the prevalence of medical emergencies in dental practice in Nepal, to assess the preparedness of dentists to manage emergency situation, to find out the ways to improve their preparedness, and to determine the factors affecting the occurrence of medical emergency.

Materials \& Method: A cross-sectional study using self-administered questionnaire was done among one hundred and twenty four participants present at the 16th Annual Dental Conference. The questionnaire consisted of 15 questions. The data were analyzed using chi-square test and cross tabulation was performed to evaluate categorical variables at a significant level of $p<0.05$.

Result: The percentage of respondents who reported at least one emergency situation was $37.1 \%$. Majority of the events occurred during oral surgical treatment. According to the survey, the most frequently encountered emergency condition was vasovagal syncope followed by hypoglycemia and seizures. The emergency events were managed by the respondents through various modalities. The dental graduates despite BLS training were found to feel incompetent to manage emergency events.

Conclusion: Medical emergencies in dental practice in Nepal are frequent and not as rare as anticipated. Thus periodic training should be provided to improve necessary clinical skills.

Keywords: medical emergency, dental practice, preparedness

\section{INTRODUCTION}

Medical emergencies occur in dental practice. Changing demographics in the population, leading to increased life expectancy has resulted in more people having medical conditions which predispose to medical emergency situations. On the other hand, many people are taking systemic medications which may influence their dental management. ' Although the occurrence of life threatening emergencies in dental office is infrequent, many factors can increase the likelihood of such incidents. ${ }^{2}$ Several studies have investigated the types, prevalence and frequency of medical emergencies occurring in dental practice and the preparedness of the operator to manage them. ${ }^{3}$ Those studies concluded that various medical emergencies occur commonly in the dental setting but severe life threatening incidents are relatively rare. The available information suggests that dental graduates across the world may not be adequately prepared to the management of medical emergencies. A New Zealand study showed more than 50 percent dentists were dissatisfied with undergraduate training for medical emergencies and Brazilian dental undergraduates were also found to be similarly dissatisfied. ${ }^{4}$ The studies conducted in UK, USA and Australia suggested the need to revise the formal training of dental practitioners in the management of medical emergencies. ${ }^{1,3,5}$ However, the perspective of dental practitioners working in Nepal is unknown due to lack of previous studies in the country. The objectives of the study are as follows:

1. To determine the prevalence of medical emergencies in dental practice in Nepal.

2. To assess the preparedness of dentist to manage emergency situation.

3. To explore ways to improve their preparedness.

4. To explore the factors associated with the occurrence of medical emergency. 


\section{MATERIALS AND METHOD}

A cross sectional study was conducted to assess prevalence and preparedness of medical emergency among Nepalese dental practitioners. As there is no previous research about how many dental practitioners might have encountered medical emergency and how effectively they could manage them, it was assumed that fifty percent of them might effectively manage such situation; which depicted the appropriate sample size. The $\mathrm{p}$-value was set at 0.05 , confidence interval at $95 \%$ and range of accuracy at $20 \%$; thus the estimated sample size for the present was ninety six. ${ }^{6}$ The study was approved by Institutional Review Committee.

A self-administered questionnaire was distributed to 200 participants present at the $16^{\text {th }}$ Annual Dental Conference of Nepal Dental Association. It is the national level conference attended by dental practitioners from various parts of the country. The respondents were requested so as to ensure good participation in the study and informed consent was duly obtained. The questionnaire consisted of 15 questions. Certain question was set in five-point Likert scale. A total of 124 filled questionnaires were received. Cross tabulation and chisquare test were performed to evaluate categorical variables at a significance level of $p<0.05$. The statistical software SPSS version 21 was used to perform statistical analyses.

\section{RESULT}

Out of the total respondents most of them were females $(59.7 \%)$ and had practice experience less than two years (46.0\%). Majority of them were of undergraduate level (64.5\%) and were in full time practice $(77.4 \%)$.

Almost $44.4 \%$ respondents reported that they can manage emergency situation at least 'well' (Table 1). Among total respondents, majority of respondents (62.9\%) reported that they had not encountered any emergency situation so far, whereas $37.1 \%$ reported that they had encountered emergency situation. The majority of dentists $(97.6 \%)$ reported that they provide dental treatment under local anesthesia.

Table 1: Distribution of responses regarding 'management of emergency situation'

\begin{tabular}{|l|c|}
\hline \multicolumn{1}{|c|}{$\begin{array}{c}\text { Can manage emergency situation in } \\
\text { dental practice (N=124) }\end{array}$} & $\begin{array}{c}\text { Percentage } \\
\mathbf{( \% )}\end{array}$ \\
\hline Extremely Well & 1.6 \\
\hline Very Well & 8.1 \\
\hline Well & 34.7 \\
\hline Not Very well & 50.0 \\
\hline Not at all & 3.2 \\
\hline No response & 2.4 \\
\hline
\end{tabular}

\section{Prevalence of medical emergencies}

According to the present report, most of the emergencies occurred during treatment (43.5\%). Majority of the emergency condition was found to be vasovagal syncope $(71.7 \%)$ followed by hypoglycemia, seizures and allergic reaction (Table 2). Respondents reported that the majority of dental procedure they were undertaking were extraction and minor oral surgery $(73.9 \%)$ followed by root canal treatment when emergency situation occurred (Table 3).

Table 2: Distribution of responses regarding 'type of emergency event'

\begin{tabular}{|l|c|}
\hline \multicolumn{1}{|c|}{ Type of emergency situation $\mathbf{( N = 4 6 )}$} & Percentage (\%) \\
\hline Syncope & 71.7 \\
\hline Hypoglycemia & 6.5 \\
\hline Seizures & 4.4 \\
\hline Allergic reaction & 4.4 \\
\hline Not specified & 13.0 \\
\hline
\end{tabular}

Table 3: Distribution of responses regarding 'type of procedure when emergency occurred'

\begin{tabular}{|l|c|}
\hline \multicolumn{1}{|c|}{$\begin{array}{c}\text { Dental procedures when emergency } \\
\text { occurred (N=46) }\end{array}$} & Percentage (\%) \\
\hline Extraction & 69.6 \\
\hline Root canal treatment & 8.7 \\
\hline Minor oral surgery & 4.3 \\
\hline Restoration & 2.2 \\
\hline Oral prophylaxis & 2.2 \\
\hline Local anesthesia & 2.2 \\
\hline Non-response & 10.8 \\
\hline
\end{tabular}

\section{Preparedness to manage emergency situation}

Most of the practitioners managed emergency condition like vasovagal syncope by placing the patient in supine position with legs elevated (71.8\%); followed by medication (type not specified) and glucose administration (Table 4).

Only $46.8 \%$ practitioners admitted that they have necessary drugs and equipment ready for medical emergency management in their working place. $84.7 \%$ reported that they have hospital back-up for medical emergency situation. 61.3\% reported they had adequate undergraduate training to manage emergency like Basic Life Support (BLS). Among the respondents with post-graduate qualification; $15.3 \%$ had accomplished BLS training during their post-graduate education. 
Table 4: Distribution of responses regarding 'how they managed emergency situation'

\begin{tabular}{|l|c|}
\hline \multicolumn{1}{|c|}{ Manage emergency situation $\mathbf{( N = 4 6 )}$} & Percentage (\%) \\
\hline Proper positioning of the patient & 71.8 \\
\hline Glucose administration & 6.5 \\
\hline Medication & 6.0 \\
\hline Referral & 4.5 \\
\hline Consultation & 2.5 \\
\hline Not reported & 8.7 \\
\hline
\end{tabular}

\section{Methods to improve emergency preparedness}

Majority of the respondents $(92.7 \%)$ are willing to improve emergency preparedness skill by attending hands-on courses. $1.6 \%$ respondents felt they do not require further training (Table 5). $88.7 \%$ respondents had no confidence in interpreting Electrocardiogram (ECG) and chest x-ray. However $8.1 \%$ specified that they were more confident in reading chest $x$ ray compared to ECG.

On the other hand, $50.8 \%$ respondents felt lack in confidence in administering intravenous, intramuscular and subcutaneous medications. However, $26.6 \%$ were reported to be confident in gaining i.m. access and $8.6 \%$ were confident in i.m. as well as s.c. medication.

Table 5: Distribution of responses regarding 'improvement in emergency preparedness'

\begin{tabular}{|l|c|}
\hline \multicolumn{1}{|c|}{ Preparedness Improvement $(\mathbf{N}=\mathbf{1 2 4})$} & Percentage (\%) \\
\hline No Need & 1.6 \\
\hline Hands-on Courses & 92.7 \\
\hline Others & 1.7 \\
\hline No response & 4.0 \\
\hline
\end{tabular}

\section{Factors associated with occurrence of medical emergency}

The study attempted to determine the relationship between variables related to medical emergencies to the characteristics of respondents. It was found that factors like gender, education, type of practice did not have association with the occurrence of medical emergencies, however undergraduate BLS training had significant relation with medical emergencies $(p<0.05)$ (Table 6).

\section{DISCUSSION}

Present study assessed the prevalence and preparedness to manage medical emergency situation in dental practice in Nepal. The percentage of respondents who encountered at least one emergency situation was $37.1 \%$; which is contrary to common belief that the medical emergencies in dental practice are uncommon. The study reported almost $70 \%$ of the emergency events occurred during exodontias; which signifies that general population has greater psychological and physiological stress with tooth extraction.

More than $50 \%$ respondents felt incompetency in managing the cardiopulmonary resuscitation (CPR) emergencies. Similar study in India also reported that dentists were not prepared to undertake CPR. ${ }^{7}$ In the present study, the most frequently encountered medical emergency was vasovagal syncope, hypoglycemia, seizures and allergic reaction. The syncope episodes were managed by following the general guidelines of positioning the patient in supine position with legs slightly elevated. The hypoglycemic events were managed by administering glucose, and seizures and minor allergic reactions were managed by proper positioning and medication. As in previous studies, the present study

Table 6: Relationship between characteristics of respondents and occurrence of medical emergency

\begin{tabular}{|c|c|c|c|c|c|}
\hline \multirow{2}{*}{\multicolumn{2}{|c|}{ Variables }} & \multicolumn{4}{|c|}{ Occurrence of Medical Emergency } \\
\hline & & \multirow{2}{*}{$\begin{array}{c}\text { No }(\mathrm{N}=\mathbf{7 8}) \\
30\end{array}$} & \multirow{2}{*}{$\begin{array}{c}\text { Yes }(\mathbf{N}=\mathbf{4 6}) \\
20\end{array}$} & \multirow{2}{*}{$\begin{array}{c}\text { Total }(\mathbf{N}=\mathbf{1 2 4}) \\
50\end{array}$} & \multirow{3}{*}{$\begin{array}{c}\text { P-value } \\
0.58\end{array}$} \\
\hline \multirow{2}{*}{ Gender } & Male & & & & \\
\hline & Female & 48 & 26 & 74 & \\
\hline \multirow{2}{*}{ Education } & BDS & 52 & 28 & 80 & \multirow{2}{*}{0.51} \\
\hline & MDS & 26 & 18 & 44 & \\
\hline \multirow{2}{*}{ Practice } & Full time & 58 & 38 & 96 & \multirow{2}{*}{0.29} \\
\hline & Part time & 20 & 8 & 28 & \\
\hline \multirow{2}{*}{ UG BLS training } & No & 37 & 13 & 50 & \multirow{2}{*}{$0.04^{*}$} \\
\hline & Yes & 41 & 33 & 74 & \\
\hline \multirow{4}{*}{ Years of Practice } & $0-2$ yrs & 38 & 19 & 57 & \multirow{4}{*}{0.07} \\
\hline & $2-5$ yrs & 17 & 9 & 26 & \\
\hline & $5-8$ yrs & 12 & 3 & 15 & \\
\hline & $>8$ yrs & 11 & 15 & 26 & \\
\hline
\end{tabular}

*Significant $p<0.05$ 
confirms that the most critical clinical situations such as acute myocardial infarction, cardiac arrest and anaphylaxis are uncommon. . $^{-19}$

In Nepalese context, only $46.8 \%$ practitioners keep emergency drugs and equipment in working place. The essential medical equipment such as oxygen cylinder must be available in breathing difficulty cases or in situations where the patient is unconscious and not ventilating properly. ${ }^{11}$ There should be professional guidelines to instruct all dental practitioners to acquire a set of critical drugs and equipment.

The study showed that, almost $84.7 \%$ respondents have hospital back-up which denotes that if the situation becomes unfavorable patient can be transferred to nearby hospitals. Since there is no 'central calling system' for emergency as in developed countries; Nepalese dental practitioners with its management team should possess information about local ambulance service.

Almost $61.3 \%$ respondents had undergraduate emergency management training of BLS, however they still felt incompetent in handling emergency events. The present result is in accordance with other studies where dental graduates felt incompetence in handling medical emergency and perform CPR. ${ }^{14}$ Majority of the respondents felt they lack confidence in gaining intravenous access, which could be due to the fact that iv access is not so routinely performed during undergraduate training. Similar results were found in the research conducted in England with regard to skill to apply injections. ${ }^{10,12}$ Majority had no confidence in interpreting ECG and chest X-ray, which highlights training requirements to reinforce the skill.

Investigations were assessed for the factors related to occurrence of medical emergency. Training in undergraduate and years of experience of respondents were associated with the occurrence of medical emergency. It could be noted that $57.6 \%$ respondents who have experience for more than 8 years came across the medical emergency more frequently.

Dental practitioners are expected to handle emergency situation by general public, even though the life threatening emergency situations may be rare. Thus the respondents were also asked how academic institutions and Nepal Dental Association can help to upgrade the knowledge and behavior of dental practitioners regarding medical emergency. Various responses were obtained such as: handson training in BLS, Continuing Dental Education, workshops and lectures. Few respondents also suggested revision in undergraduate curriculum to incorporate course modules of medical emergency with simulation lab for BLS and practice with emergency drills. The BLS training provides basic skill to manage medical emergencies, which comprises assessment of the patient, treatment of airway, breathing and circulation (CABs of cardiopulmonary resuscitation). Usually, the dentist should consider the use of emergency drugs only after CABs is performed. ${ }^{20,21}$

\section{CONCLUSION}

Medical emergencies in dental practice in Nepal are considerable and not as rare as anticipated. The percentage of dentists who encountered at least one emergency situation is $37.1 \%$. Majority of the events occur during oral surgical treatment predominantly exodontia. The most frequently encountered emergency situation is vasovagal syncope followed by hypoglycemia and seizures. Regular participation in BLS courses specially designed for dentists should be undertaken to improve clinical skills in medical emergency.

\section{ACKNOWLEDGEMENT}

Authors would like to thank NDA for providing the platform to conduct the study. 


\section{REFERENCES}

1. Atherton GJ, Mc Caul JA, Williams SA. Medical emergencies in general dental practice in Great Britain. Part I: Their prevalence over a ten year period. Br Dent J 1999; 186:72-9.

2. Malamed SF. Medical emergencies in the dental office. 6th ed. St Louis, MO: Mosby, 2000.

3. American Dental Association Council on Dental Practice. The U.S approach to dental emergency preparedness and disaster response. ADA Council on Government Affairs. J Am Dent Assoc. 2009; 140(5):546-7.

4. Newby JP, Keast J, Adam WR. Simulation of medical emergencies in dental practice: Development and evaluation of an undergraduate training program. Aus Dent J 2010; 55: 399-404.

5. Chapman PJ. Medical emergencies in dental practice and choice of emergency drugs and equipment: A survey of Australian dentists. Aus Dent J 1997; 42:103-8.

6. Lwanga KS, Lemeshow S. Sample size determination in health studies A practical manual WHO Geneva 1991:25

7. Gupta T, Aradhya MR, Nagaraj A. Preparedness for management of medical emergencies among dentists in Udupi and Mangalore India. J Contemp Dent Pract. 2008; 9(5):92-9.

8. Morse Z, Murthi VK. Medical emergencies in dental practice in the Fiji Islands. Pac Health Dialog. 2004; 11 (1):55-8.

9. Arsati F, Montalli VA, Flório FM, Ramacciato JC, da Cunha FL, Cecanho R, de Andrade ED, Motta RH. Brazilian dentists' attitudes about medical emergencies during dental treatment. J Dent Educ. 2010; 74(6):661-6.

10. Atherton GJ, Mc Caul JA, Williams SA. Medical emergencies in general dental practice in Great Britain. Part 3: Perceptions of training and competence of GDPs in their management. Br Dent J. 1999; 186(5):234-7.

11. Rosenberg M. Preparing for medical emergencies: The essential drugs and equipment for the dental office. J Am Dent Assoc. 2010; 141:14-9s.

12. Atherton GJ, Pemberton MN, Thornhill MH. Medical emergencies: The experience of staff of a UK dental teaching hospital. Br Dent J 2000; 188(6):320-4.

13. Malamed SF. Medical emergencies in the dental surgery. Part 1: Preparation of the office and basic management. J Ir Dent Assoc 2015; $61(6): 302-8$.

14. Alhamad M, Alnahwi T, Alshayeb H, Alzayer A, Aldawood O, Almarzouq A, Nazir MA. Medical emergencies encountered in dental clinics: A study from the Eastern Province of Saudi Arabia. J Family community Med. 2015; 22(3):175-9.

15. Neumar TW, Otto CW, Link MS. Part 8: Adult advanced cardiovascular life support-2010. American Heart Association Guidelines for cardiopulmonary resuscitation and emergency cardiovascular care. Circulation. 2010; 122:S729-67.

16. Neumar RW, Shuster M, Callaway CW. Part 1: Executive summary-2015. American Heart Association Guidelines Update for Cardiopulmonary Resuscitation and Emergency Cardiovascular Care. Circulation. 2015; 132(suppl 2):S315-67.

17. Müller MP, Hänsel M, Stehr SN, Weber S, Koch T. A state- wide survey of medical emergency management in dental practices: Incidence of emergencies and training experience. Emerg Med J 2008; 25:296-300.

18. Becker DE. Emergency drug kits: Pharmacological and technical considerations. Anesth Prog. 2014; 61:171-9.

19. Kleinman ME, Brennan EE, Goldberger ZD. Part 5: Adult basic life support and cardiopulmonary resuscitation quality: 2015 American Heart Association Guidelines Update for Cardiopulmonary resuscitation and Emergency Cardiovascular Care. Circulation.2015; 132 (Suppl 2): S414-35.

20. Marks LA, Van Parys C, Coppens M, Herregods L. Awareness of dental practitioners to cope with a medical emergency: A survey in Belgium. Int Dent J 2013; 63:312-6.

21. Al-Sebaei MO, Alkayyal MA, Alsulimani AH, Alsulaimani OS, Habib WT. The preapredness of private dental offices and polyclinics for medical emergencies. A survey in western Saudi Arabia. 2015; 36(3):335-40. 